\title{
Trabalhonecessário
}

ISSN: 1808 - 799X

ANO 12, № 19 - 2014

\section{CONSIDERAÇÕES SOBRE O TRABALHO COMO PRINCÍPIO EDUCATIVO E A EDUCAÇÃO COMO INSTRUMENTO DE RESISTÊNCIA E EMANCIPAÇÃO}

\author{
Paulo Eduardo Dias Taddei ${ }^{1}$ \\ Vanessa Gonçalves Dias 2 \\ Andréa Wahlbrink Padilha da Silva ${ }^{3}$
}

RESUMO: O presente trabalho tem por objetivo realizar uma reflexão sobre a importância do trabalho como elemento constituinte de um projeto de educação integral, tendo por base o seguinte questionamento: qual a modalidade de trabalho e a forma de escola que, articulados, podem contribuir para a construção de uma educação como instrumento de resistência e emancipação humana? Esta é a questão norteadora deste artigo, que busca problematizar o papel do trabalho enquanto elemento central para o desenvolvimento do trabalho pedagógico nas escolas públicas.

Palavras-chave: Trabalho, Educação e Emancipação.

ABSTRACT: This paper aims to carry out a reflection on the importance of work as a constituent element of a draft comprehensive education, based on the following question: what kind of work and the way to school, articulated, can contribute to the construction of an education as a tool of resistance and human

\footnotetext{
${ }^{1}$ Mestre em educação, integrante do grupo de pesquisa MoVse: Educação Popular e Escola

Pública e Movimentos Sociais e colaborador do Observatório da Educação - Núcleo RS FaE/UFPel. E-mail: paulopiratini@bol.com.br

${ }^{2}$ Mestre em educação,integrante do grupo de pesquisa MoVse: Educação Popular e Escola Pública e Movimentos Sociais e colaboradora do Observatório da Educação - Núcleo RS FaE/UFPel. E-mail: vanygd@yahoo.com.br

${ }^{3}$ Mestranda do programa de pós-graduação em Educação, integrante do grupo de pesquisa MoVse: Educação Popular e Escola Pública e Movimentos Sociais e bolsista do projeto do Observatório dả Educação - Núcleo RS - FaE/UFPel. E-mail: andreawahlbrink@hotmail.com
} 


\section{Trabalhonecessário}

ISSN: 1808 - 799X

ANO 12, № 19 - 2014

emancipation? These are some of the issues developed throughout this article, we seek to problematize the role of work as a central element for the development of pedagogical work in public schools.

Keywords: Work, Education and Emancipation.

\section{INTRODUÇÃO}

Em primeiro lugar, inobstante a centralidade do trabalho como fundamento do ser social, não é qualquer forma de trabalho que pode ser considerada como princípio educativo, conforme será discutido neste texto. Com efeito, o trabalho que degrada, que bestializa, que aliena, não pode servir de princípio para a construção de um projeto de educação emancipatória.

Por outro lado, não é qualquer projeto de educação que emancipa, pois os espaços formais ou não - formais de educação tanto podem se constituir em um nicho de resistência quanto de reprodução do paradigma hegemônico.

O presente texto tem por objetivo realizar uma reflexão sobre a importância do trabalho como elemento constituinte de um projeto de educação integral, tendo por base o seguinte questionamento: qual a modalidade de trabalho e a forma de escola que, articulados, podem contribuir para a construção de uma educação como instrumento de resistência e emancipação?

No primeiro item discutiremos a finalidade principal do processo ensino/aprendizagem, no qual é feita uma breve análise da educação formal capitalista, para, posteriormente, no segundo, tecer algumas considerações sobre o trabalho como princípio educativo, buscando analisar a modalidade de trabalho que pode servir como princípio educativo. No último item, pretende-se elaborar um breve ensaio sobre o que vem a ser uma educação como instrumento de resistência e emancipação. Ao final é feita uma breve conclusão.

TrabalhoNecessário - www.uff.br/trabalhonecessario; Ano 12, № 19/2014. 


\section{Trabalhonecessário}

ISSN: 1808 - 799X

ANO 12, № 19 - 2014

O presente artigo é bibliográfico. A pesquisa é qualitativa e tem 0 pensamento marxista como matriz teórica, conforme se pode observar pelas obras e textos arrolados nas referências bibliográficas.

\section{A ESCOLA COMO ESPAÇO DE REPRODUÇÃO DOS POSTULADOS DO SISTEMA HEGEMÔNICO}

Antes de começar qualquer análise sobre a importância do trabalho como elemento constituinte de um projeto de educação integral e refletir sobre a educação como instrumento de resistência e emancipação é necessário definir, com a devida clareza, a função da escola. Esta discussão pode até parecer dispensável, à primeira vista, mas se a proposta deste trabalho é analisar qual o tipo de trabalho e qual o modelo de educação que, articulados, podem contribuir para a construção de uma educação como instrumento de resistência e emancipação, é necessária esta análise prévia para a construção de um alicerce sólido para o ulterior desenvolvimento deste texto.

Hoje, no Brasil, a escola pública, de uma forma geral, está sucateada e, evidentemente, não oferece um ensino de qualidade. Este sucateamento não é só de ordem material, como, por exemplo, prédios em péssimas condições e equipamentos (cadeiras, mesas, vidros, iluminação, sistema de ventilação, etc.) também em situação precária. O sucateamento é, também, de ordem imaterial, com uma inversão da lógica da escola, que ao invés de ser um local de construção do conhecimento, de uma forma crítica e transformadora, é um nicho assistencialista e, em grande medida, de reprodução do modelo social dominante.

O direito à educação gratuita e universal é resultado da luta da classe trabalhadora. Todavia, se por um lado esse processo foi responsável pela

TrabalhoNecessário - www.uff.br/trabalhonecessario; Ano 12, № 19/2014. 


\title{
Trabalhonecessário
}

ISSN: 1808 - 799X

ANO 12, № 19 - 2014

massificação da educação, ampliando o acesso; por outro, não garantiu uma educação de qualidade para os filhos e filhas dos trabalhadores e trabalhadoras. Neste sentido, diz Frigotto (2010):

\begin{abstract}
Uma escolaridade elementar que permita um nível mínimo de cálculo, leitura e escrita, e o desenvolvimento de determinados traços socioculturais, políticos e ideológicos tornam-se necessários para a funcionalidade das empresas produtivas e organizações em geral, como também para a instauração de uma mentalidade consumista (FRIGOTTO, 2010, p. 183)
\end{abstract}

Com efeito, a escola pública vem assumindo uma variada gama de funções, ficando a base fundamental do processo de ensino-aprendizagem, que é a transmissão dos conhecimentos acumulados historicamente pela humanidade, em plano secundário ou em posição semelhante às demais atividades desenvolvidas na escola.

Juntamente com este fato, o conhecimento sistematizado é transmitido superficialmente e de forma divorciada da realidade concreta dos principais protagonistas desse processo: alunos e professores, resultando, quando muito, na internalização acrítica dos conteúdos "depositados" em sala de aula. Sobre a função da escola, refere Franco (1988, p. 57):

O papel precípuo da escola é a transmissão de conhecimentos. Não conhecimentos enciclopédicos, abstratos, mas conhecimentos vivos e concretos, indissoluvelmente ligados às experiências de vidas dos alunos e às exigências históricas da sociedade presente. $O$ papel da escola, pois, é fundamentalmente transmitir, de maneira lógica, coerente e sistemática, os conhecimentos acumulados historicamente pelo homem, ou seja, os conhecimentos científicos, tecnológicos, filosóficos, culturais, etc., indissoluvelmente ligados à experiência dos alunos e às realidades sociais mais amplas.

No mesmo sentido, diz Saviani (2003, p. 15): 


\title{
Trabalhonecessário
}

ISSN: 1808 - 799X

ANO 12, № 19 - 2014

A escola existe, pois, para propiciar a aquisição dos instrumentos que possibilitam o acesso ao saber elaborado (ciência), bem como o próprio acesso aos rudimentos desse saber. As atividades da escola básica devem organizar-se a partir dessa questão. Se chamarmos isso de currículo, poderemos então afirmar que é a partir do saber sistematizado que se estrutura o currículo da escola elementar. Ora, o saber sistematizado, a cultura erudita, é uma cultura letrada. Daí que a primeira exigência para o acesso a esse tipo de saber seja aprender a ler e escrever. Além disso, é preciso conhecer também a linguagem dos números, a linguagem da natureza e a linguagem da sociedade. Está aí o conteúdo fundamental da escola elementar: ler, escrever, contar, os rudimentos das ciências naturais e das ciências sociais (história e geografia humanas).

Assim, se não há dúvidas, por um lado, que a função da escola é efetivamente a transmissão de conhecimentos historicamente acumulados, por outro, esta função não pode se restringir somente a isso, devendo ir além, através da articulação desses mesmos conhecimentos com a realidade cotidiana concreta dos alunos, ou seja, com a própria experiência deles, pois, do contrário se cai em um processo de transmissão mecanicista, no qual o aluno é objeto, mero receptor do conhecimento depositado pelo professor, que "tudo sabe". Sobre isso, assevera Franco (1988, p. 57):

\begin{abstract}
A transmissão dos conhecimentos historicamente acumulados pelo homem é necessária, mas não suficiente para compreender a verdadeira função de uma escola que pretenda dar sua contribuição para a construção do socialismo. A educação escolar não pode ser reduzida à pura transmissão de conhecimentos. Os conhecimentos transmitidos devem ser "vivos e concretos", e não conhecimentos abstratos, autônomos, como se os mesmos tivessem vida própria, independentemente das condições históricos-sociais. Estar atento para esse fato é condição sinequa non para que a prática educacional não caia na mistificação.
\end{abstract}

Acrescenta, ainda, Franco (1988, p. 58):

Os conhecimentos devem ser antes de tudo, reflexão sobre o próprio modo de vida social e não mera assimilação, por parte do aluno, de conhecimentos concebidos como autônomos e colocados como culturais em si mesmos. Os conhecimentos transmitidos pela escola

TrabalhoNecessário - www.uff.br/trabalhonecessario; Ano 12, № 19/2014. 


\section{Trabalhonecessário}

ISSN: 1808 - 799X

ANO 12, № 19 - 2014

devem estar, assim, diretamente articulados com os comportamentos humanos e as formas como as sociedades concretas se organizam e, particularmente, devem estar articulados com a experiência de vida dos alunos.

Assim, feitas estas breves considerações sobre a função primordial da escola, passa-se a seguir, a uma reflexão sobre a escola como local de reprodução dos postulados do sistema hegemônico.

Os espaços formais de educação historicamente se constituem em local de reprodução do pensamento hegemônico, através de projetos políticopedagógicos e de "práticas sociais naturalizadas" que culminam na "legitimação" do sistema dominante, dificultando, dessa forma, a implantação de qualquer outro projeto ou concepção que represente uma ameaça a essa hegemonia. Com efeito, em regra, esses espaços trabalham com um projeto educacional, em sentido amplo, que mais aliena do que emancipa, ancorado em princípios pedagógicos e metodológicos que desprezam a realidade concreta do educando, dando prevalência ao "conteúdo pelo conteúdo", mais voltado para o depósito de conhecimentos pré-estabelecidos, do que para a construção coletiva de novas formas de compreensão do mundo e da realidade, com a finalidade de formar homens e mulheres livres e pensantes, capazes de lutar para a superação de uma realidade que os desumaniza.

Todavia, de outro lado, nesses espaços de reprodução da ideologia dominante, estão presentes as contradições inerentes ao sistema que eles representam, possibilitando, destarte, o exercício da resistência ao modelo dominante. Desta forma, diz Franco (1988, p. 55):

Concretamente a escola desempenha um papel preponderante no sentido de conservação da estrutura social vigente, ainda que, como foi assinalado, seu papel não se restrinja a isso. A escola, em verdade, desempenha um importante papel no sentido de formar (e

TrabalhoNecessário - www.uff.br/trabalhonecessario; Ano 12, № 19/2014. 


\section{Trabalhonecessário}

ISSN: 1808 - 799X

ANO 12, № 19 - 2014

aprimorar) a força de trabalho, ratificar as desigualdades sociais, inculcar a ideologia dominante, ou seja, no sentido de difundir crenças, idéias, valores, etc., compatíveis com a ordem social estabelecida. A maneira como isso se dá, no entanto, não está imune a certas contradições e, por isso, entra em choque com a própria perpetuação das condições sociais existentes.

A educação capitalista, portanto, é um instrumento de manutenção da hierarquia social, ou seja, de reprodução das ideias da classe dominante. Neste sentido, dizem Marx e Engels (2009, p. 78):

As ideias (Gedanken) da classe dominante são, em todas as épocas, as idéias dominantes; ou seja, a classe que é a força material dominante da sociedade é, ao mesmo tempo sua força espiritual dominante. A classe que dispõe dos meios de produção material dispõe também dos meios de produção espiritual, o que faz com que sejam a ela submetidas, ao mesmo tempo, as idéias daqueles que não possuem os meios de produção espiritual. As idéias dominantes, são, pois, nada mais que a expressão ideal das relações materiais dominantes, são essas as relações materiais dominantes compreendidas sob a forma de idéias; são, portanto, a manifestação das relações que transformam uma classe em classe dominante; são dessa forma, as idéias de sua dominação. Os indivíduos que formam a classe dominante possuem, entre outras coisas, também uma consciência e, por conseguinte, pensam; uma vez que dominam como classe e determinam todo o âmbito de um tempo histórico, é evidente que o façam em toda a sua amplitude e, como conseqüência, também dominem como pensadores, como produtores de idéias, que controlem a produção e a distribuição das idéias de sua época, e que suas idéias sejam, por conseguinte, as idéias dominantes de um tempo.

A resistência, na escola, acontece através da construção de um projeto político-pedagógico contra-hegemônico, que parte de um saber não dissociado da realidade, aproveitando-se das próprias contradições do sistema dominante. Assim, conforme Paludo (2012):

A categoria resistência vem sendo a chave de leitura para um 'novo processo pedagógico' para a construção de uma nova escola. A resistência dos 'de baixo', daqueles que sempre tiveram o mínimo ou quase nada para viver, a resistência a um sistema que os inclui

TrabalhoNecessário - www.uff.br/trabalhonecessario; Ano 12, № 19/2014. 


\section{Trabalhonecessário}

ISSN: 1808 - 799X

ANO 12, № 19 - 2014

deixando-os de fora, inclusive da escola, por que o que está em disputa é a lógica que gesta a sociedade, e consequentemente a escola.

Dessa maneira, mesmo que o movimento da realidade, neste contexto histórico, ainda não apresente, em curto prazo, uma possibilidade concreta de superação do modelo societário vigente, ainda assim é indispensável o exercício da resistência ao modelo hegemônico. E, conformefoi dito, a resistência pode - e deve - ser trabalhada sobre as próprias contradições do sistema que é reproduzido na escola.

O espaço formal de educação, no contexto atual, não rompendo com o "modelo bancário" 4 de educação, dentro de uma concepção metafísica e idealista de mundo, não pode ser visto como um nicho para a formação de uma consciência-crítica - nem se fala em consciência revolucionária -, pois, em regra, ele reproduz o paradigma hegemônico da sociedade na qual está inserido.

\section{O TRABALHO COMO PRINCÍPIO EDUCATIVO: QUAL O TRABALHO?}

O trabalho, no seu sentido ontológico, é o fundamento do próprio ser social, porque ele está na base do processo de construção do próprio homem, segundo Engels (2013). Diz o referido autor: "O trabalho é a fonte de toda riqueza, afirmam os economistas. Assim é, com efeito, ao lado da natureza, encarregada de fornecer os materiais que ele converte em riqueza. $O$ trabalho, porém, é muitíssimo mais do que isso. É a condição básica e fundamental de toda a vida humana. E em tal grau, até certo ponto, podemos afirmar que 0 trabalho criou o próprio homem" (Engels, 2013, p. 13).

\footnotetext{
${ }^{4}$ Categoria utilizada por Paulo Freire na obra Pedagogia do Oprimido.

TrabalhoNecessário - www.uff.br/trabalhonecessario; Ano 12, № 19/2014.
} 


\section{Trabalhonecessário}

ISSN: 1808 - 799X

ANO 12, № 19 - 2014

Partindo, desta mesma concepção do trabalho, indaga Tumolo (2005, p. 241):

Se é verdade que o trabalho é a base da existência humana, penso que seria necessário indagar como é produzida essa existência humana, por intermédio do trabalho, na especificidade do modo capitalista de produção. Qual é, nesta forma social determinada, o significado do trabalho? Em que medida seria possível considerar o trabalho como princípio balizador de uma proposta emancipadora de educação no interior do capitalismo?

Ora, no "mundo do capital", o trabalho ganha outra dimensão, deixando de ser um trabalho concreto, útil ou vivo, no momento em que a força de trabalho se converte em mercadoria. Neste sentido, diz Tumolo (2005, p. 247248):

Todavia, o encontro entre força de trabalho e meios de produção, cuja finalidade é produzir valores de uso, não tem, em princípio, um caráter capitalista, uma vez que tal relação é condição eterna da humanidade para produzir sua vida em qualquer forma societal. Por esta razão, de início, Marx dá um tratamento genérico aos meios de produção no interior do processo de trabalho, já que, per se, eles não têm uma natureza capitalista e só adquirem este conteúdo histórico quando a força de trabalho que os utiliza se transformou numa mercadoria, ou seja, quando se estabelece a especificamente capitalista, cuja condição essencial é a conversão da força de trabalho em mercadoria. Em suma, nesse momento de sua trajetória analítica, o autor está fazendo uma explanação do processo simples

de trabalho.

Assim, não é qualquer forma de trabalho que pode ser considerada como princípio educativo. Com efeito, o trabalho que explora, que aliena, que degrada, que bestializa, por óbvio, não pode servir de princípio para a construção de um projeto de educação emancipatória, muito pelo contrário, porque dessa forma a escola ficaria subordinada às exigências do capital. 


\title{
Trabalhonecessário
}

ISSN: 1808 - 799X

ANO 12, № $19-2014$

Confirmando esta afirmação, diz Franco (1988, p. 82): "A escola, assim, não pode se subordinar às exigências efêmeras dos setores produtivos, à preparação profissional imediata e à competição e ao individualismo da sociedade capitalista".

A partir dessas considerações, pergunta-se: que tipo de trabalho pode se constituir em princípio educativo? Tumolo (2005, p. 252), respaldado em $O$

Capital, fala de três formas de trabalho: "trabalho útil ou concreto, como criador de valor de uso, trabalho abstrato, como substância de valor e, finalmente, trabalho produtivo de capital".

Sobre esta última modalidade de trabalho, diz Tumolo (2005, p. 252):

"Numa leitura preliminar, este último deve ser considerado, entre eles, a categoria analítica determinante, pois além de pressupor os dois primeiros, expressa o conjunto de contradições do processo de produção especificamente capitalista".

Retomando a questão sobre o tipo de trabalho que pode se constituir em princípio educativo, diz Frigotto (2005):

\begin{abstract}
Do ponto de vista educativo, o esforço das forças progressistas deve caminhar no sentido da escola unitária, onde se possa pensar o trabalho de modo que o sujeito não seja o mercado e, sim, o mercado seja uma dimensão da realidade social. Trata-se de pensar o trabalho em outro contexto social, no qual o trabalhador produza para si, e onde 0 produto do trabalho coletivo se redistribua igualmente (FRIGOTTO, 2005, p.76).
\end{abstract}

Assim, não é possível enxergar, no modelo capitalista, o trabalho como princípio educativo. Tal poderá ocorrer em outro modelo de sociedade, mas não neste, pois o trabalho capitalista propriamente dito, ao invés de emancipar, aliena o trabalhador.

É necessário esclarecer também que no estágio atual do capitalismo, qualquer tentativa de implantação do trabalho capitalista como princípio

TrabalhoNecessário - www.uff.br/trabalhonecessario; Ano 12, № 19/2014. 


\section{Trabalhonecessário}

ISSN: 1808 - 799X

ANO 12, № 19 - 2014

educativo resultará na preparação do educando para competir por uma vaga num mercado de trabalho assentado na alienação e na exploração.

Nada mais!

Ademais, não se quer dizer que não exista relação entre sociedade e escola; escola e sociedade, com influências recíprocas, de uma sobre a outra, com maior grau de influência da sociedade sobre a escola. O que se quer dizer que a influência da sociedade sobre a escola não é absoluta, podendo esta, inclusive, se transformar em um nicho de resistência ao paradigma daquela. Com efeito, o que não é possível é conceber a forma de trabalho capitalista como princípio educativo para uma escola emancipadora, como, também, não é aceitável transformar a escola em um espaço de preparação para o mercado. Feitas estas breves reflexões sobre a natureza do trabalho que pode constituir-se em princípio educativo, passa-se, no item seguinte: à discussão acerca da forma de escola que possibilita a construção de uma educação como instrumento de resistência e emancipação.

\section{UMA EDUCAÇÃO COMO INSTRUMENTO DE RESISTÊNCIA E EMANCIPAÇÃO: QUAL EDUCAÇÃO PARA OS TRABALHADORES?}

O que podemos considerar como uma educação como instrumento de resistência e emancipação? Já foi visto que a escola capitalista não oferece 0 modelo educacional para a emancipação, posto que, de uma forma geral, é reprodutora do modelo social hegemônico, alicerçado na exploração, na opressão, na exclusão e na alienação. Contudo, por outro lado, nesses espaços de reprodução da ideologia dominante, estão presentes as contradições inerentes ao sistema que eles representam, possibilitando, destar- 


\title{
Trabalhonecessário
}

ISSN: 1808 - 799X

ANO 12, № 19 - 2014

te, o exercício da resistência ao modelo hegemônico.

Ora, como nada é eterno, tudo está em constante devir no processo histórico. Assim, não sendo o capitalismo como algo dado e imutável, o modelo educacional capitalista também não é imutável, como uma determinação sobrenatural, não passível de transformação.

A escola, se por um lado, não é uma ilha isolada no âmbito das relações sociais do modelo capitalista, por outro, não é determinada de forma absoluta por essas relações, podendo, portanto, constituir-se num espaço de luta pela hegemonia, como forma de resistência às determinações do capital, buscando superar o processo de reificação do homem, que está no "DNA" do sistema capitalista, no qual a mercadoria se humaniza e o homem se coisifica. Neste sentido, diz Franco (1988, p 82):

\begin{abstract}
As relações da escola com o mercado de trabalho não são estreitas, racionais, simples, unidirecionais, de causa e efeito, mas sim dialéticas, onde escola não se encontra inteiramente subordinada às leis e mecanismos de funcionamento do mercado de trabalho. As tentativas de adequar a escola às exigências do mercado de trabalho não têm passado de um esforço vão. No fundo, as análises que têm procurado caracterizar o mercado de trabalho têm repousado em pressupostos falsos, ou seja, de que o mesmo é estático, homogêneo, fechado, a-histórico, quando, em verdade, o mercado de trabalho é uma realidade histórica, socialmente determinada, e que obedece a movimentação desordenada do capital.
\end{abstract}

Assim, não há dúvidas de que é possível a superação de um modelo social desumanizante, por uma práxis emancipatória. Para se entender o que é educação emancipatória é necessário, antes de qualquer coisa, buscar o conceito de emancipação em Marx. Este conceito pode ser extraído da obra "A questão judaica”, na qual Marx trabalha com os conceitos de emancipação polí- 


\title{
Trabalhonecessário
}

ISSN: 1808 - 799X

ANO 12, № $19-2014$

tica e emancipação humana. Aqui interessa o conceito de emancipação humana.

Marx (2006, p. 24) diz que "a emancipação política representa um enorme progresso. Porém, não constitui a forma final de emancipação humana, mas é a forma final desta emancipação dentro da ordem mundana até agora existente. Não será necessário dizer que estamos aqui discorrendo sobre a emancipação real, prática".

A emancipação humana, em síntese, é a emancipação plena, integral do ser humano, ou seja, quando o homem, na expressão de Marx, "se tiver tornado um ser genérico" (Idem, p. 37). Articulando as duas formas de emancipação, afirma Marx (2006, p. 37):

\begin{abstract}
A emancipação política é a redução do homem, por um lado, a membro da sociedade civil, indivíduo independente e egoísta e, por outro, a cidadão, a pessoa moral. Só será plena a emancipação humana quando o homem real e individual tiver em si o cidadão abstrato; quando como homem individual, na sua vida empírica, no trabalho e nas suas relações individuais, se tiver tornado um ser genérico; e quando tiver reconhecido e organizado as suas próprias forças (forces properes) como forças sociais, de maneira a nunca mais separar de si esta força social como força política.
\end{abstract}

A emancipação humana, portanto, consiste no desenvolvimento integral do ser humano; na superação de sua condição de "homem dividido", unilateral. A unilateralidade é, com efeito, segundo Manacorda (1991, p. 68-69), o resultado da divisão social do trabalho no sistema capitalista, conforme enuncia o seguinte fragmento:

A divisão do trabalho, ou a propriedade privada, tornou-nos obtusos e unilaterais. A divisão cria a unilateralidade e, sob o signo da unilateralidade, justamente, se reúnem todas as determinações negativas, assim como sob o signo oposto da onilateralidade(obviamente, muito menos freqüente, dada que essa 


\title{
Trabalhonecessário
}

ISSN: 1808 - 799X

ANO 12, № 19 - 2014

não é ainda cosa deste mundo) reúnem-se todas as perspectivas positivas da pessoa humana.

Para Marx e Engels (2004, p. 68), a educação integral ou omnilateral, abrange três aspectos:

\begin{abstract}
Por educação entendemos três coisas: Educação intelectual
Educação corporal, tal como a que se consegue com os exercícios de ginástica e militares Educação tecnológica, que recolhe os princípios gerais de caráter científico de todo o processo e produção e, ao mesmo tempo, inicia as crianças e os adolescentes no manejo de ferramentas, elementares dos diversos ramos industriais.

À divisão das crianças e adolescentes em três categorias, de nove a dezoito anos, deve corresponder um curso graduado e progressivo para sua educação intelectual, corporal e politécnica. Os gastos com tais escolas politécnicas serão parcialmente cobertos com a renda de seus próprios produtos.

Esta combinação de trabalho produtivo pago com a educação intelectual, os exercícios corporais e a formação politécnica elevará a classe operária acima dos níveis das classes burguesa e aristocrática. O emprego de crianças e adolescentes de nove a dezoito anos em trabalhos noturnos ou em indústrias, cujos efeitos sejam nocivos à saúde deve ser severamente proibido por lei.
\end{abstract}

Manacorda (1991, p. 68-69), fala da oposição entre a educação mnilateral e a educação unilateral:

\begin{abstract}
A divisão do trabalho, ou a propriedade privada, tornou-nos obtusos e unilaterais. A divisão cria unilateralidade e, sob o signo da unilateralidade, justamente, se reúnem todas as determinações negativas, assim como sob o signo oposto da onilateralidade (obviamente, muito menos freqüente, dado que essa não é ainda coisa deste mundo) reúnem-se todas as perspectivas positivas da pessoa humana.
\end{abstract}

A emancipação humana é, portanto, um processo de superação do estado de unilateralidade, resultado da divisão do trabalho, através de um salto qualitativo para um estado de omnilateralidade, ou seja, de totalização do homem, de desenvolvimento pleno de suas lateralidades, numa síntese de totali- 


\title{
Trabalhonecessário
}

ISSN: 1808 - 799X

ANO 12, № 19 - 2014

dade.

Sobre a omnilateralidade, diz Manacorda (1991, p. 81):

\begin{abstract}
A omnilateralidade é, portanto, a chegada histórica do homem a uma totalidade de capacidades produtivas e, ao mesmo tempo, uma totalidade de capacidades de consumo e prazeres, que se deve considerar sobre todo o bojo daqueles bens espirituais, além dos materiais, e dos quais os trabalhadores tem estado excluídos, em consequência da divisão do trabalho (MANACORDA, 1991, p. 81).
\end{abstract}

A educação pode ser o caminho mais sóbrio, racional e mesmo revolucionário para a transformação, embora isoladamente não possa fazer tudo. A educação para a emancipação consiste na construção coletiva de novas formas de compreender o mundo, e, a partir desta compreensão, intervir na realidade com a finalidade de formar homens e mulheres livres e pensantes, capazes de lutar para a superação de uma situação que os desumaniza.

A educação para a emancipação, portanto, é aquela que busca um novo projeto político-pedagógico, com uma nova concepção de educação, uma educação transformadora. Não a educação que aliena, reproduzindo o modelo das classes dominantes, mais precisamente dos interesses do capital, mas a educação que conscientiza através da realidade concreta dos protagonistas do processo ensino/aprendizagem, sem mistificações, que faz com que o oprimido entenda sua situação no contexto social, econômico, político e cultural onde está inserido, conhecendo, sobretudo, as causas reais dessa situação e as possibilidades de transformação a partir desse entendimento.

\section{CONSIDERAÇÕES}

TrabalhoNecessário - www.uff.br/trabalhonecessario; Ano 12, № 19/2014. 


\section{Trabalhonecessário}

ISSN: 1808 - 799X

ANO 12, № 19 - 2014

Retoma-se, aqui a pergunta norteadora deste trabalho: "qual a modalidade de trabalho e a forma de escola que, articulados, podem contribuir para a construção de uma educação como instrumento de resistência e emancipação?" Em primeiro lugar, o trabalho que constitui a tríade da educação omnilteral (intelectual, física e politécnica) não é o trabalho histórico, abstrado, morto, do modelo capitalista, mas o trabalho ontológico, vivo e concreto.

Em segundo lugar, a educação para a emancipação não é aquela que reproduz o modelo do sistema hegemônico, mas aquela que se apresenta, como um projeto contra-hegemônico, ou seja, uma educação crítica, voltada para a construção de uma nova consciência social, com base, principalmente, na liberdade, na igualdade substancial (equidade) e na solidariedade, comoações superadoras do autoritarismo, da igualdade formal (liberal) e do individualismo.

Em suma, é uma educação voltada para a superação da exploração, da opressão e da alienação, bases fundantes do capitalismo, juntamente com o lucro, o desenvolvimento a qualquer custo e o individualismo exacerbado.Neste sentido, preleciona Mészáros (2008, p. 71): "A educação para além do capital visa uma ordem social qualitativamente diferente". Diz, ainda: "Não pode haver uma solução efetiva para a autoalienação do trabalho sem que se promova, conscienciosamente, a universalização conjunta do trabalho e da educação" (Idem, 2008, p. 67).

Assim, a articulação entre o trabalho em seu sentido ontológico, como princípio educativo, e a educação intelectual, cuja função é a transmissão de conhecimentos acumulados historicamente, sem desprezar a realidade concreta dos sujeitos envolvidos no processo de ensino/aprendizagem, podem contribuir de forma efetiva para a construção de uma educação como instrumento de 


\section{Trabalhonecessário}

ISSN: 1808 - 799X

ANO 12, № 19 - 2014

resistência e emancipação, sem olvidar a educação corporal ou física, como integrante dessa articulação.

A partir da compreensão do trabalho como elemento fundante do ser social, será possível entender a importância de sua utilização na organicidade da escola pública, em todas as suas dimensões: ao pensar seu projeto político pedagógico, seu currículo, seus métodos e metodologias. Tudo isso, na direção de proporcionar aos educandos das escolas públicas uma nova concepção de mundo, de sujeito, de educação e de sociedade, em uma perspectiva crítica e dialógica da realidade objetiva na sociedade de classes.

Frigotto, Ciavatta e Ramos (2005) afirmam que a atuação da escola não deve ser pensada de forma a-histórica e abstrata, mas, pensada e gestada organicamente na perspectiva da contra-hegemonia, vinculada as lutas sociais mais amplas na direção da emancipação. É preciso educar para uma leitura crítica e reflexiva da realidade, mas, para isso, é necessário um processo educativo que proporcione aos sujeitos experiências significativas, desde as suas singularidades individuais, até àquelas que envolvam questões coletivas, com o objetivo de ir além da compreensão de suas condições de vida, para poder intervir de forma autônoma e crítica na sociedade.

\section{REFERÊNCIAS}

ENGELS, Friedrich. Sobre o papel do trabalho na transformação do macaco em homem. In ANTUNES, Ricardo (Org.). A dialética do trabalho: escritos de Marx e Engels. São Paulo: Expressão Popular, 2013.

FRANCO, Luiz Antonio Carvalho. E escola e o trabalho e o trabalho da escola. 2 ${ }^{a}$ Ed., São Paulo: Cortez: Autores Associados, 1988, III Parte. 


\section{Trabalhonecessário}

ISSN: 1808 - 799X

ANO 12, № 19 - 2014

FRIGOTTO, Gaudêncio, CIAVATTA, Maria e RAMOS, Marise. O trabalho como princípio educativo no projeto de educação integral dos trabalhadores. In: COSTA, Hélio da e CONCEIÇÃO, Martinho. Educação integral e sistema de reconhecimento e certificação educacional profissional. São Paulo: Secretaria Nacional de Formação - CUT, 2005.

FRIGOTTO, Gaudêncio. A Produtividade da escola improdutiva. São Paulo, Cortez, 2010.

MANACORDA, Mario Alighiero. Marx e a pedagogia moderna. São Paulo: Cortez: Autores Associados, 1991.

MARX, Karl e ENGELS, Friedrich. A Ideologia Alemã: Feuerbach - a contraposição entre as cosmovisões materialista e idealista - São Paulo: 3a Ed., Martin Claret, 2009 (Coleção Obra-Prima de cada Autor).

MARX, Karl . A questão judaica. In: Manuscritos Econômico-filosóficos. São Paulo - SP: Martin Claret Ltda., 2006.

MARX, Karl e ENGELS, Friedrich. Textos sobre educação e ensino. São Paulo: Centauro, 2004.

MARX, Karl e ENGELS, Friedrich. Crítica da educação e do ensino. Com introdução e notas de Roger Dangeville. Lisboa: Moraes Editores, 1978.

MÉSZÁROS, István. A educação para além do capital. $2^{\underline{a}}$ Ed. - São Paulo: Boitempo, 2008.

PALUDO, Conceição. MACHADO, Rita. SILVA, Andrea. Construção da escola pública e popular como processo de resistência. In Marx e a Educação - Trabalho natureza e conflitos. Porto Alegre: Evangraf, 2012.

SAVIANI, Dermerval. Pedagogia histórico-crítica: primeiras aproximações. - 8. ed. - Campinas, SP: Autores Associados, 2003 (Coleção educação contemporânea).

TUMOLO, Paulo Sérgio. O trabalho na forma social do capital e o trabalho como princípio educativo: uma articulação possível? Educ. Soc., Campinas, vol. 26, n. 90, p.239-265, Jan/Abr, 2005.

Recebido em: 30/08/2014

Aprovado em: 28/10/2014 